\title{
Penentuan Nilai Ekonomi Taman Nasional Gunung Ciremai Dengan Metode Contingen Valuation Method
}

\author{
Ali Al Madaidy dan Iwan Juwana \\ Jurusan Teknik Lingkungan, Fakultas Teknik Sipil dan Perencanaan, ITENAS Bandung \\ Email: juwana.itenas.ac.id
}

\begin{abstract}
ABSTRAK
Taman Nasional Gunung Ciremai (TNGC) di Jawa Barat merupakan kawasan konservasi dan salah satu wisata alam di Indonesia. Pengelolaan Taman Nasional Gunung Ciremai (TNGC) Jalur Pendakian Apuy dikelola oleh Mitra Pariwisata Gunung Ciremai (MPGC) Argamukti dan didampingi oleh Seksi Pengelola Taman Nasional II (SPTN II) resort Argalingga. Menjadi destinasi pendakian gunung oleh wisatawan menimbulkan permasalahan tersendiri bagi TNGC sebagai sebuah kawasan hutan. Permasalahan yang timbul antara lain adalah sampah yang dibawa oleh pengunjung taman nasional yang tidak terkelola dengan baik. Selain itu, keterbatasan pengetahuan dan keterbatasan dana yang dihadapi oleh pengelola menambah pelik permasalahan persampahan di area wisata ini. Salah satu alasan dilakukannya penelitian ini adalah belum adanya penelitian mengenai Willingness to pay (WTP) untuk pengelolaan persampahan di Taman Nasional Gunung Ciremai. Contingent Valuation Method (CVM) yang digunakan dalam penelitian ini dimaksudkan untuk menentukan nilai WTP dan nilai tersebut nantinya dijadikan sebagai informasi awal biaya untuk pengelolaan persampahan di Taman Nasional Gunung Ciremai Hasil penelitian ini menunjukan bahwa rataan WTP responden wisatawan berdasarkan CVM adalah sebesar Rp. 13.646, - atau Rp. 200.996.776 /tahun.
\end{abstract}

Kata kunci: Willingness to Pay, Travel Cost Method, Contingent Valuation Method, Taman Nasional Gunung Ciremai.

\begin{abstract}
Mount Ciremai National Park (TNGC) in West Java is a conservation area and one of nature tourism in Indonesia. The Apuy Track in Mount Ciremai National Park are managed by Argamukti's Ciremai Mountain Ascent Community (MPGC) and accompanied by Section II of The National Park Management (STPN II) Argalingga resort. Being a mountain climbing destination raises its own problems for TNGC as a forest. The problems that arise include visitors wastes in national parks are not properly managed. Furthermore, limited knowledge and funds which is faced by the management are increasing the waste problems in this tourism area. One of the reason of this study is the research on Willingness to Pay (WTP) for solid waste management still rare in Mount Ciremai National Park. Contingent Valuation Method (CVM) are used to determine the WTP value and it will be used as first information for waste management costs in Mount Ciremai National Park. The results of this research shown that the average WTP of tourist respondents based on CVM is Rp. 13.646,- or Rp. 200.996.776,- /year.
\end{abstract}

Keywords: Willingness to Pay, Travel Cost Method, Contingent Valuation Method, Mount Ciremai National Park. 


\section{PENDAHULUAN}

Pembangunan bidang pariwisata merupakan salah satu sektor yang nampaknya perlu mendapatkan perhatian serius, terutama dalam menciptakan pariwisata yang bernuansa lingkungan seperti ekowisata. Ekowisata ini adalah upaya memadukan konservasi, masyarakat dan pembangunan berkelanjutan, wisatawan digambarkan melakukan perjalanan wisata alami secara bertanggung jawab untuk melakukan upaya konservasi lingkungan dan mendukung kesejahteraan masyarakat lokal [1].

Taman Nasional Gunung Ciremai (TNGC) adalah gunung tertinggi di Jawa Barat dengan ketinggian 3.078 mdpl. TNGC merupakan kawasan konservasi yang menjadi tujuan wisata/ pendakian yang popular bagi wisatawan nusantara. Pada tahun 2004, sesuai Surat Keputusan Menteri Kehutanan No. 424/Menhut-II/2004, kawasan yang memiliki luas $+15.500 \mathrm{Ha}$ ini beralih fungsi dari hutan lindung dan hutan produksi menjadi Taman Nasional atau dikenal dengan Taman Nasional Gunung Ciremai (TNGC) [2].

TNGC memiliki persoalan lingkungan yang belum dapat diatasi. Taman Nasional Gunung Ciremai termasuk dalam kategori 17 gunung yang tercemar oleh sampah pendaki pada tahun 2017. Oleh karena itu, berdasarkan instruksi dari Kementrian Lingkungan Hidup dan Kehutanan (KLHK) melalui Direktur Pengelolaan Persampahan KLHK, dibuat pedoman mengenai pengumpulan, pengangkutan, pemrosesan, dan daur ulang sampah pendaki. Namun, karena keterbatasan dana dan pengetahuan dari pengelola, menyebabkan permasalahan persampahan sulit teratasi ditambah belum adanya kajian mengenai willingness to pay yang bisa dijadikan salah satu cara mengatasi masalah yang ada di Taman Nasional Gunung Ciremai.

Oleh karena itu, perlu dilakukan pengkajian Willingness to pay (WTP) Taman Nasional Gunung Ciremai (TNGC). Pengkajian WTP dengan metode Contingent Valuation Method (CVM) ini dilakukan untuk mengetahui nilai moneter yang bersedia di bayarkan untuk perbaikan pengelolaan persampahan oleh pendaki yang datang. Hasil pengkajian tersebut diharapkan dapat digunakan oleh pengelola TNGC untuk memperbaiki atau meningkatkan sarana dan prasarana di TNGC.

Metode yang digunakan untuk mengidentifikasi besaran nilai ekonomi di TNGC pada penelitian ini adalah Contingent Valuation Method (CVM). Metode CVM dipilih untuk menentukan Willingness to Pay berdasarkan bidding. Contingent Valuation Method (CVM) merupakan metode valuasi sumber daya alam dan lingkungan dengan cara menanyakan secara langsung kepada konsumen mengenai nilai manfaat yang didapat. Nilai ekonomi sumber daya alam dan lingkungan dapat diperoleh dengan menanyakan kesanggupan membayar (willingness to pay) yang dapat dinyatakan dengan satuan uang [3].

\section{TINJAUAN PUSTAKA}

\subsection{Ekowisata}

Definisi ekowisata pertama kali diperkenalkan oleh The Ecotourism Society pada tahun 1990 , yaitu ekowisata merupakan bentuk perjalanan wisata menuju area alami yang dilakukan dengan tujuan mengkonservasi lingkungan dan melestarikan kehidupan dan kesejahteraan penduduk setempat.

Berdasarkan definisi tersebut, ekowisata menekankan kepada pentingnya menjaga dan melestarikan lingkungan dan juga memperhatikan sosial ekonomi masyarakat yang berada di area wisata. konsep ekowisata ada beberapa aspek kunci yang perlu diperhatikan yaitu: 
- Adanya pembatasan jumlah pengunjung supaya sesuai dengan daya dukung lingkungan dan sosial budaya masyarakat.

- Pola wisata yang ramah lingkungan dan memperhatikan nilai konservasi.

- Pola wisata ramah budaya dan adat setempat (nilai edukasi dan wisata).

- Membantu secara langsung perekonomian masyarkat lokal (nilai ekonomi).

- Pembangunan tidak menghabiskan biaya yang besar (nilai pastisipasi masyarakat dan ekonomi) [1].

\subsection{Teknik Sampling}

Pengambilan sampel harus respresentatif atau mewakili populasi yang dijadikan bahan penelitian. Salah satu teknik sampling yang dapat digunakan adalah non probability sampling. Teknik ini tidak memberikan peluang atau kesempatan yang sama kepada setiap anggota populasi, dalam teknik ini salah satu cara menentukan responden adalah sampling purposive. Sampling purposive ini menentukan sampel dengan pertimbangan tertentu [4].

Penentuan ukuran sampel banyak pendekatan, salah satu pendekatan yang dapat digunakan adalah pendekatan Slovin. Melalui pendekatan ini peneliti diberikan kebebasan memilih level kepercayaan sendiri antara $90 \%$ sampai dengan $100 \%$.

Jumlah sampel data primer yang dikumpulkan ditentukan berdasarkan jumlah pengunjung terakhir. Penentuan jumlah sampel dihitung menggunakan rumus slovin sebagai berikut:

Dimana :

$$
\mathrm{n}=\frac{N}{1+N e^{2}}
$$

$\mathrm{N}=$ Rata-rata pengunjung rentang tahun

$\mathrm{n}=$ Jumlah sampel

$\mathrm{e}=$ tingkat kesalahan yang diinginkan

\subsection{Analisis Deskriptif}

Analisis deskriptif merupakan suatu metode penelitian yang bertujuan untuk memberikan gambaran atau mendeskripsikan terhadap suatu objek berdasarkan data dan fakta yang dikumpulkan secara sistematis yang dianalisis untuk mendapatkan kesimpulan. Fungsi dari penggunaan analisis ini adalah untuk menerangkan keadaan, gejala, atau persoalan yang didapat dari pengumpulan data. Penarikan kesimpulannya didasarkan pada kumpulan data yang ada [5].

\subsection{Nilai Ekonomi}

Nilai ekonomi secara umum didefinisikan sebagai pengukuran jumlah maksimum dari seseorang mau mengorbankan barang dan jasa untuk memperoleh barang dan jasa lainnya. Secara formal biasa disebut dengan keinginan orang untuk membayar (willingness to pay) seseorang terhadap barang dan jasa yang dihasilkan oleh sumberdaya alam dan lingkungan. Nilai ekologis dari ekosistem yang digunakan diukur dengan Bahasa ekonomi dengan mengukur nilai moneter dari barang dan jasa. Dengan kata lain, kerusakan yang terjadi pada suatu lingkungan dan ekosistem nilainya dapat diukur dari keinginan seseorang untuk membayar agar kembali pulihnya lingkungan dan ekosistem tersebut seperti aslinya atau mendekati aslinya [6].

Pengukuran nilai sumberdaya, dilakukan berdasarkan konsep nilai total (total value) yaitu nilai kegunaan atau pemanfaatan (use value) dan nilai bukan kegunaan atau non use value. Dengan 
mengetahui nilai sumberdaya tersebut, seharusnya kita dapat memanfaatkan sumberdaya secara efisien. Oleh karena itu, perlu diketahui nilai ekonomi total atau total economic value (TEV) dari sumberdaya tesebut [6].

Alasan mengapa satuan moneter diperlukan dalam valuasi ekonomi sumberdaya alam dan lingkungan. Adalah sebagai berikut [7]:

- Satuan moneter dapat digunakan untuk menilai tingkat kepedulian seseorang terhadap lingkungan;

- Satuan moneter dari manfaat dan biaya sumberdaya alam dan lingkungan dapat menjadi pendukung untuk keberpihakan terhadap kualitas lingkungan;

- Satuan moneter dapat dijadikan sebagai bahan pembanding secara kuantitatif terhadap beberapa alternatif suatu kebijakan tertentu termasuk pemanfaatan sumberdaya alam.

\subsection{Contingent Valuation Method (CVM)}

Contingent Valuation Method (CVM) adalah metode valuasi berdasarkan survei yang digunakan untuk memberi penilaian moneter pada komoditas lingkungan berdasarkan besar pengunjung mau membayar untuk perbaikan kualitas lingkungan. Ide yang mendasari metode ini adalah wisatawan memilik prefensi yang tersembunyi untuk semua komoditas lingkungan, sehingga diasumsikan bahwa orang-orang memiliki kemampuan untuk mentransformasikan prefensi-prefensi yang dimiliki kedalam satuan moneter [8].

\subsection{Bagan Alir Penelitian}

\section{METODOLOGI}

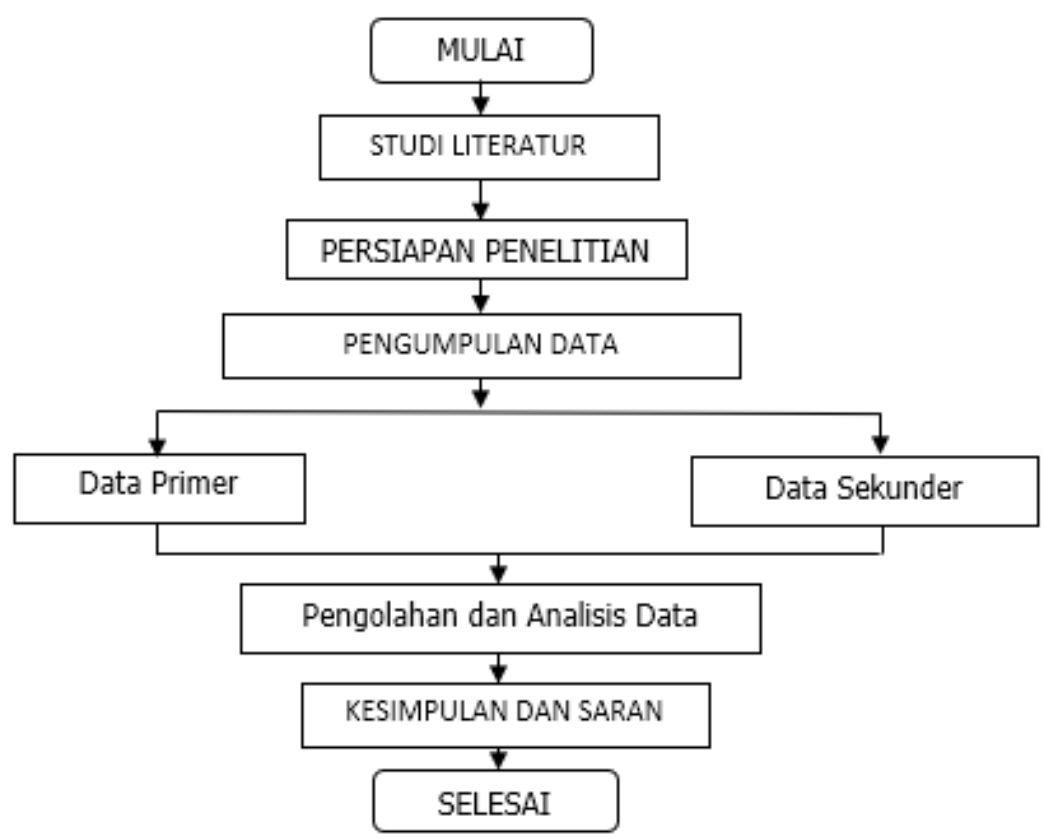

Gambar 1 Bagan Alir Metodologi Penelitian

Gambar 1 menunjukkan bagan alir metodologi pada penelitian ini. Penelitian ini dilakukan di Taman Nasional Gunung Ciremai dalam kawasan Seksi Pengelolaan Taman Nasional (SPTN), Wilayah 2, Jalur Pendakian Apuy, Kabupaten Majalengka. 


\subsection{Studi Literatur}

Studi literatur dilakukan terhadap berbagai literatur mengenai valuasi ekonomi. Pustaka yang digunakan berasal dari literatur buku, internet ataupun peraturan-peraturan yang dikeluarkan Pemerintah Republik Indonesia. Hasil dari studi literatur ini digunakan untuk memahami valuasi yang dianalisis.

\subsection{Persiapan Penelitian}

Persiapan penelitian dilakukan dengan beberapa tahapan persiapan, yaitu mengumpulkan informasi TNGC Jalur Pendakian Apuy melalui wawancara dengan pihak Balai Taman Nasional Gunung Ciremai (BTNGC) dan pengelola dari Mitra Pariwisata Gunung Ciremai (MPGC), kemudian menentukan variabel berdasarkan literatur terkait dan hasil pengamatan langsung di TNGC Jalur Pendakian Apuy, dan melakukan perancangan kuesioner.

\subsection{Tahapan Pengumpulan Data}

Pengumpulan data dilakukan melalui 2 tahapan, yaitu :

a. Data Primer

Pengumpulan data primer dilakukan untuk mendapatkan data lingkungan fisik TNGC, data biaya perjalanan, WTP dengan bidding game, dan data sosial ekonomi. Pengumpulan data primer tersebut dilakukan dengan cara melakukan wawancara dengan pengelola, pengamatan langsung di lapangan, dan melalui kuesioner kepada sampel dari para pendaki.

b. Data Sekunder

Pengumpulan data sekunder ini meliputi Gambaran umum TNGC, jumlah pengunjung yang terdata di TNGC, data biaya yang dikenakan kepada pengunjung, dan sarana prasarana di TNGC. Data sekunder ini diperoleh dari BTNGC dan MPGC.

\subsection{Pengolahan dan Analisis Data}

Pengolahan dan analisis data pada penelitian ini dilakukan tahapan-tahapan sebagai berikut:

\subsubsection{Analisis Deskriptif}

Metode deskriptif adalah suatu metode penelitian yang bertujuan untuk memberikan gambaran atau mendeskripsikan terhadap suatu objek berdasarkan data dan fakta yang dikumpulkan secara sistematis yang dianalisis untuk mendapatkan kesimpulan.

Analisis ini berfungsi untuk menerangkan keadaan, gejala, atau persoalan yang didapat dari perkumpulan data. Penarikan kesimpulannya didasarkan pada data yang dikumpulkan.

\subsubsection{Contingent Valuation Method (CVM)}

Menilai valuasi bukan pasar (non-market) untuk mendapatkan informasi WTP individu memiliki beberapa metode yang bisa digunakan, salah satu yang biasa digunakan adalah Contingent Valuation Method [9]. Nilai WTP dengan CVM didapatkan secara langsung (terungkap) baik secara tulisan maupun lisan [6].

Tahapan-tahapan dalam metode CVM adalah sebagai berikut [10]:

a. Membuat pasar hipotetik

Pasar hipotetik ini dibuat untuk memberikan gambaran jelas mengenai permasalahan yang terjadi kepada pengunjung sekaligus memberikan gambaran perbaikan yang ditawarkan kepada pengunjung dengan konsekuensi pengunjung mau ikut berkontribusi secara materi dalam perbaikan tersebut. 
b. Penawaran besarnya nilai Willingness to Pay (WTP)

Penawaran besarnya WTP dilakukan dengan metode bidding game. Bidding game ini digunakan untuk memudahan responden dalam melakukan evaluasi lingkungan [11]. Keuntungan bidding game dalam mendapatkan penawaran besarnya nilai WTP adalah membantu responden mempertimbangkan refrensi mereka secara hati-hati [12]. Kerugian dari bidding game adalah penawaran (nilai) pembukaan yang disajikan dijadikan sebagai pembayaran maksimum mereka. Masalah ini disebut sebagai starting point [13].

c. Memperkirakan nilai rata-rata WTP

Dugaan rataan WTP dihitung dengan rumus:

$$
E W T P=\frac{\sum_{i=l}^{n} \mathrm{WI}}{n}
$$

Dimana:

$$
\begin{array}{ll}
\text { EWTP } & =\text { Dugaan rataan WTP } \\
\text { Wi } & =\text { Nilai WTP ke- } \mathrm{i} \\
\mathrm{n} & =\text { Jumlah Responden } \\
\mathrm{i} & =\text { Responden ke-i yang bersedia membayar }(\mathrm{i}=1,2 \ldots \mathrm{n})
\end{array}
$$

d. Menjumlahkan Data

Penjumlahan data ialah proses perubahan nilai rata-rata penawaran terhadap total keputusan penjumlahan data.

$$
T W T P=\sum_{i=l}^{n} W T P i\left(\begin{array}{c}
n i \\
N
\end{array}\right) \mathrm{P}
$$

Dimana:

TWTP $=$ Total WTP

WTP $\mathrm{i}=$ WTP individu sampel ke-i

ni $\quad=$ Jumlah sampel ke-i yang bersedia membayar sebesar WTP

$\mathrm{N} \quad=$ Jumlah sampel

$\mathrm{P} \quad=$ Jumlah Populasi

$\mathrm{i} \quad=$ Responden Ke-i yang bersedia membayar

\subsection{Penentuan Jumlah Responden}

\section{HASIL DAN PEMBAHASAN}

Pengumpulan data wisatawan dilakukan untuk mengetahui karakteristik pendaki, keinginan dalam berkontribusi terhadap masalah pengelolaan persampahan di Taman Nasional Gunung Ciremai (TNGC), Jalur Pendakian Apuy. Penentuan jumlah responden di lokasi penelitian digunakan rumus slovin dalam [14], yaitu sebagai berikut :

$$
\mathrm{n}(8 \%)=\frac{N}{1+N e^{2}}=\frac{14.825}{1+\left(14.825 \times(0.08)^{2}\right)}=154.62 \approx 155 \text { Responden }
$$

Metode pengambilan sampling ini dilakukan dengan menggunakan metode non-probability sampling dan penentuan pendaki yang dijadikan responden dilakukan secara judgement atau purposive sampling, yaitu penentuan responden yang dipilih berdasarkan kriteria tertentu. Dalam hal ini, kriteria yang 
digunakan adalah pendaki yang sudah mencapai puncak Ciremai melewati Jalur Pendakian Apuy dan bersedia untuk diwawancarai. Nilai error yang digunakan adalah $8 \%(0,08)$ atau tingkat kepercayaan adalah sebesar $92 \%$, hal ini dikarenakan waktu dan biaya dalam melakukan sampling yang terbatas apabila nilai error lebih kecil akan berdampak kepada lebih banyaknya waktu dan biaya yang diperlukan.

\subsection{Analisis Deskriptif}

Analisis deskriptif merupakan analisis yang berfungsi sebagai pemberi gambaran karakteristik pengunjung yang diteliti melalui data sampel [15]. Karakteristik pendaki didasarkan kepada karakteristik sosial ekonomi dari pendaki. Karakteristik pendaki Taman Nasional Gunung Ciremai (TNGC) dapat dilihat (Tabel 1) dibawah ini:

Tabel 1. Hasil Analisis Deskriptif

\begin{tabular}{|c|c|c|c|c|}
\hline No & Karakteristik & Kategori & Frekuensi & Persentase \\
\hline \multirow{2}{*}{1} & \multirow{2}{*}{ Jenis Kelamin } & a. Laki-laki & 134 & $86 \%$ \\
\hline & & b. Perempuan & 21 & $14 \%$ \\
\hline \multirow{6}{*}{2} & \multirow{6}{*}{ Usia } & a. $17-23$ Tahun & 117 & $75 \%$ \\
\hline & & b. 24 - 30 Tahun & 28 & $18 \%$ \\
\hline & & c. 31 - 37 Tahun & 8 & $5 \%$ \\
\hline & & d. 38 - 44 tahun & 2 & $1 \%$ \\
\hline & & e. 45 - 50 tahun & 0 & $0 \%$ \\
\hline & & f. $>50$ tahun & 0 & $0 \%$ \\
\hline \multirow{4}{*}{3} & \multirow{4}{*}{ Pendidikan } & a. SD/ Sederajat & 0 & $0 \%$ \\
\hline & & b. SMP/ Sederajat & 12 & $8 \%$ \\
\hline & & c. SMA/ Sederajat & 117 & $75 \%$ \\
\hline & & d. Perguruan Tinggi & 26 & $17 \%$ \\
\hline \multirow{4}{*}{4} & \multirow{4}{*}{ Pekerjaan } & a. Pelajar / Mahasiswa & 120 & $77 \%$ \\
\hline & & b. Wiraswasta & 5 & $3 \%$ \\
\hline & & c. PNS/ Karyawan Swasta & 30 & $19 \%$ \\
\hline & & d. Lainnya & 0 & $0 \%$ \\
\hline \multirow{4}{*}{5} & \multirow{4}{*}{ Penghasilan } & a. $<1.000 .000$ & 21 & $14 \%$ \\
\hline & & b. Rp. $1.000 .000-<$ Rp. 3.000 .000 & 104 & $67 \%$ \\
\hline & & c. Rp. $3.000 .000-<$ Rp. 5.000 .000 & 26 & $17 \%$ \\
\hline & & d. $>5.000 .000$ & 4 & $3 \%$ \\
\hline \multirow{4}{*}{6} & \multirow{4}{*}{ Jarak Pengunjung } & a. $<10 \mathrm{~km}$ & 3 & $2 \%$ \\
\hline & & b. $10-50 \mathrm{~km}$ & 69 & $45 \%$ \\
\hline & & c. $51-100 \mathrm{~km}$ & 52 & $34 \%$ \\
\hline & & d. $>100 \mathrm{~km}$ & 31 & $20 \%$ \\
\hline \multirow{4}{*}{7} & \multirow{4}{*}{ Jumlah Kunjungan } & a. 1 kali & 125 & $81 \%$ \\
\hline & & b. 2 kali & 21 & $14 \%$ \\
\hline & & c. 3 kali & 8 & $5 \%$ \\
\hline & & d. $>3$ kali & 1 & $1 \%$ \\
\hline \multirow{4}{*}{8} & \multirow{4}{*}{ Jenis Kendaraan } & a. Sepeda motor & 98 & $63 \%$ \\
\hline & & b. Mobil pribadi & 4 & $3 \%$ \\
\hline & & c. Angkutan Umum & 53 & $34 \%$ \\
\hline & & d. Lainnya, ....... & 0 & $0 \%$ \\
\hline
\end{tabular}

Sumber: Hasil Pengolahan Data, 2018 


\subsection{Contingent Valuation Method (CVM)}

Metode Contingent valuation Method digunakan untuk mengetahui seberapa besar pendaki mau membayar (WTP) terhadap perbaikan persampahan yang ada di Taman nasional Gunung Ciremai. Hal ini sesuai dengan pendapat [6], menyatakan CVM pada hakikatnya bertujuan untuk mengetahui keinginan membayar (WTP) dari masayrakat, terhadap perbaikan kualitas lingkungan.

Kelebihan dalam penggunaan CVM dari teknik valuasi lain adalah kapasitas CVM yang dapat menduga nilai bukan manfaat (non use value) dari kegiatan pendakian yang ada di Taman Nasiona Gunung Ciremai [10].

\subsubsection{Membuat Pasar Hipotetik}

Pasar Hipotetik dibuat untuk memberikan gambaran kepada pendaki mengenai kondisi tidak adanya pengelolaan secara tepat terhadap sampah yang dihasilkan oleh pendaki. Sampah yang dihasilkan hanya dikumpulkan dan dibakar saja. Upaya pengelolaan yang direncanakan berdasarkan kebutuhan dijadikan penawaran kepada responden untuk ikut berpartisipasi dalam bentuk biaya yang ingin dikeluarkan.

Gambaran pasar hipotetik dapat dilihat pada Gambar 2. di bawah ini:

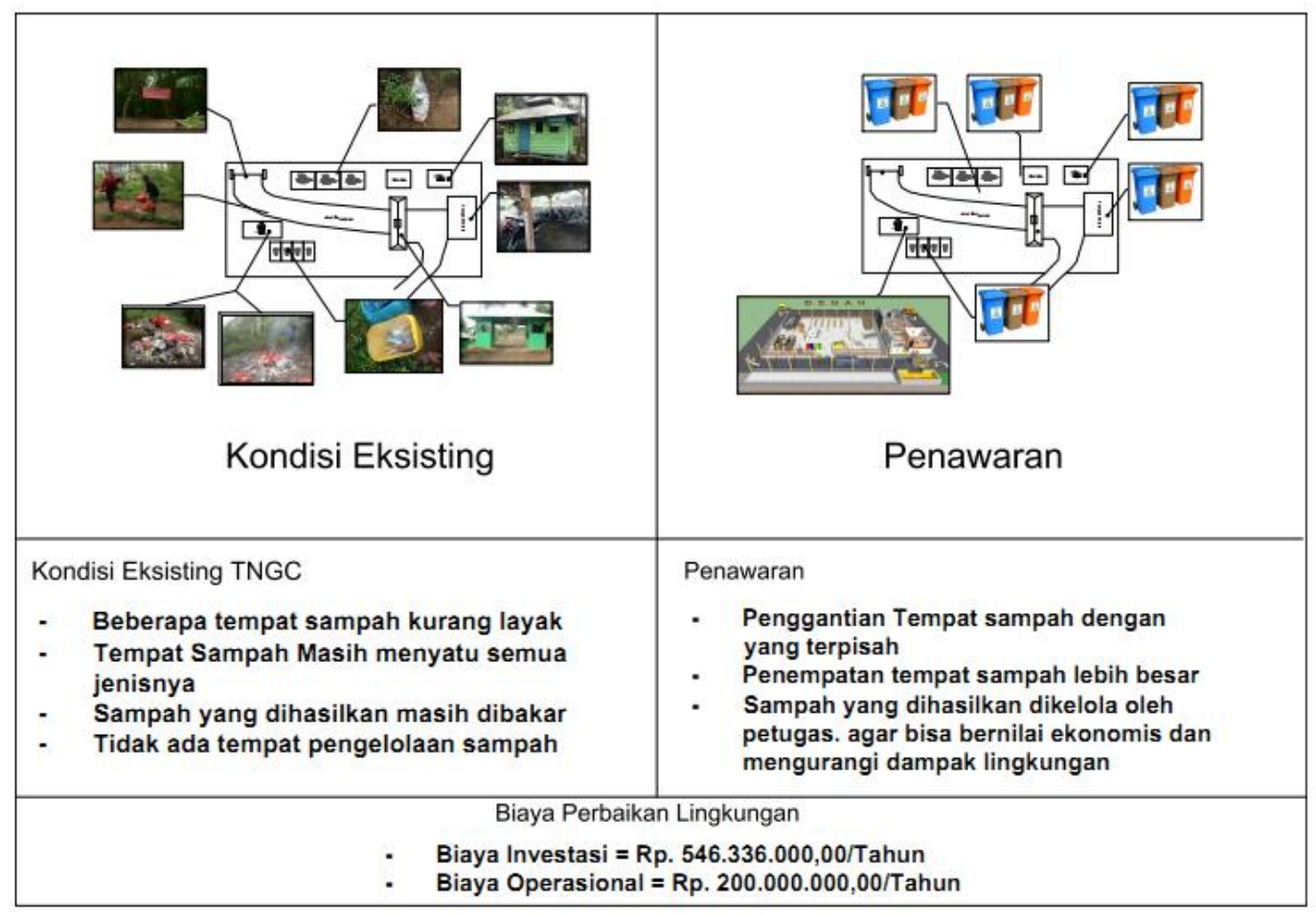

Gambar 2. Pasar Hipotetik

Penggunaan media gambar (Gambar 2) dalam pasar hipotetik ini didasarkan pada kondisi aktual yang terjadi di TNGC. Hal ini untuk menghindari kesalahan pasar hipotetik dan memberikan gambaran secara realistik kepada responden, hal ini sesuai dengan pendapat [10], yang menyatakan pasar hipotetik harus kredibel dan realistik.

\subsubsection{Mendapatkan Penawaran Besarnya Nilai WTP}

Penawaran besarnya WTP dilakukan dengan metode wawancara dengan bantuan kuesioner. Nilai WTP yang ditawarkan menggunakan metode bidding game. Nilai bidding minimal yang ditawarkan adalah 
sebesar Rp. 10.000,00 dan kenaikan setiap Rp. 2.500,00. Harga bidding ini didasarkan atas asumsi bahwa harga tersebut merupakan harga yang relevan untuk pengelolaan persampahaan di TNGC.

\subsubsection{Memperkirakan Rata-rata WTP}

Hasil mendapatkan bid dari setiap responden berarti didapat pula WTP setiap responden. Rataan WTP yang didapat sebagai berikut:

$$
\begin{gathered}
\mathrm{EWTP}=\frac{R p \cdot 2 \cdot 115 \cdot 000,00}{155 \text { orang }} \\
E \mathrm{WTP}=R p \cdot 13 \cdot 646,00
\end{gathered}
$$

Hasil dari perhitungan tersebut diketahui rataan WTP pengunjung adalah sebesar Rp. 13.646,00 /orang. Rataan WTP ini yang disarankan untuk dijadikan sebagai biaya tambahan untuk pengelolaan persampahan yang ada di TNGC.

\subsubsection{Menjumlahkan Data}

Proses penjumlahan data WTP merupakan konversi rataan WTP menjadi WTP total terhadap populasi. Total WTP ini didapat sebagai berikut:

$$
\begin{aligned}
\text { TWTP }= & R p .13 .646 \times\left(\frac{154}{155}\right) \times 14.825 \text { orang } / \text { tahun } \\
& \text { TWTP }=\text { Rp. } 200.996 .776 / \text { tahun }
\end{aligned}
$$

Hasil penjumlahan data diketahui bahwa untuk pengelolaan persampahan setiap tahun yang bersedia dibayarkan oleh pendaki adalah sebesar Rp. 200.996.776,00/tahun. Nilai ini merupakan nilai non use value, nilai bukan manfaat ini menggambarkan penilaian responden (pendaki) terhadap permasalahan persampahan yang tidak teratasi untuk keberlanjutan sumberdaya Taman Nasional Gunung Ciremai.

Nilai Willingness to pay ini bisa dijadikan pertimbangan untuk kebijakan pengelola dalam mengatasi permasalahan kekurangan biaya dalam mengelola persampahan yang ada di Taman Nasional Gunung Ciremai.

\section{KESIMPULAN}

1. Jumlah responden yang digunakan pada penelitian ini adalah sebesar 155 responden. Perhitungan yang digunakan untuk menghitung jumlah sampel adalah rumus Slovin dengan error sebesar 8\%.

2. Pengunjung yang datang mayoritas didominasi oleh Laki-laki dengan rentang usia 17-23 tahun dan bertatus sebagai pelajar/ mahasiswa.

3. Nilai bukan manfaat Taman Nasional Gunung Ciremai Jalur Pendakian Apuy adalah sebesar Rp. 200.996.776,00 /tahun yang diarahkan untuk pengelolaan persampahan.

4. Nilai WTP yang didapat menggambarkan penilaian pendaki terhadap permasalahan yang terjadi yaitu mengenai persampahan, Nilai ini dapat digunakan untuk menilai kepedulian seseorang terhadap lingkungan [7]. 


\section{SARAN}

1. Membatasi kuota pendakian untuk mengurangi beban lingkungan di Taman Nasional Gunung Ciremai.

2. Nilai WTP ini bisa dijadikan sebagai pertimbangan pengelola untuk mengatasi pengelolaan persampahan yang belum terlaksana karena permasalahan pendanaan.

3. Memberikan edukasi kepada pendaki mengenai pentingnya menjaga kualitas lingkungan untuk keberlanjutan sumberdaya di Taman Nasional Gunung Ciremai.

4. Dilakukan pembimbingan kepada pengelola mengenai persampahan agar pedoman dari KLHK yang dibuat dapat berjalan dengan baik.

\section{DAFTAR PUSTAKA}

[1] TIES (The International Ecotourism Society). 2015. TIES Brochure

[2] Keputusan Kementrian Kehutanan. 2004. SK No. 424/Menhut-II/2004 tentang Perubahan Fungsi Hutan Lindung dan Hutan Produksi Menjadi Taman Nasional Gunung Ciremai.

[3] Nasir, Mohd. 2009. Metode Penelitian. Jakarta: Ghalia Indonesia

[4] Sugiyono. 2011. Metode Penelitian Kuantitatif, Kualitatif dan R\&D. Bandung: Afabeta

[5] Whitney, F. L. 1960. The Elements of Resert. Overseas Book Co. Osaka

[6] Fauzi, Akhmad. 2004. Ekonomi Sumber Daya Alam dan Lingkungan: Teori dan Aplikasi. Jakarta: PT Gramedia Pustaka Utama.

[7] Suparmoko, 2000. Keuangan Negara: Teori dan Praktek. BPFE-Yogyakarta. Hal 4,44-45.

[8] d'Arge, R.C. 1985. Environmental Quality Benefits Research for the Next Five Years: Some Observations and recommendation, Draft Report to the U.S. Environmental Protection Agency, Washington D. C.

[9] Ulibarri, H. E. Westerdhal, P. F. Ricci and H. E Seely, M. J. Scott, G. Bilyard, S. O. Link, C. A. 1998. Valuation of ecological resources and functions, Env. Management, 22: 49 - 68.

[10] Hanley, N and C.L. Spash. 1993. Cost Benefit Analysis and Environmental. Edward Elger. Publishing . England: Hardin, Garret.

[11] Davis, R. K. 1963. The Value of Outdoor Recreation: An Economic Study of the Maine Woods, PhD Dissertation, Harvard University.

[12] Hoehn, J. P., dan Randall, A., 1983. Incentives and Performances in Contingent Policy Valuation: Paper presented at the American Agricultural Economics Association Summer Meetings, Purdue University

[13] Bishop, R. C. dan Heberlein, Th. A. 1979. Measuring Values of Extra-Markets-Goods: Are Indirect Measured Biased ?, American Journal of Agricultural Economics 61, 926-930.

[14] Fandeli, C. 2002. Perencanaan Kepariwisataan Alam. Yogyakarta: Fakultas Kehutanan Universitas Gadjah Mada.

[15] Sugiyono. 2007. Metode Penelitian Kuantitatif, Kualitatif dan R\&D. Bandung: Afabeta 